\title{
Gemi Pervanelerinde Kavitasyon Kaynaklı Gürültü ve Farklı İz Alanlarının Pervane Performansına Etkisinin İncelenmesi
}

\author{
Serkan EKINCí ${ }^{1}$ \\ 1Yyldız Teknik Üniversitesi, Gemi İnşaatı ve Denizcilik Fakültesi, Gemi İnşaatı ve Gemi \\ Makineleri Mühendisliği Bölümü, 34349, İstanbul
}

(Alınıs / Received: 21.10.2016, Kabul / Accepted: 31.03.2017, Online Yayınlanma / Published Online: 02.05.2017)

\begin{abstract}
Anahtar Kelimeler Özet: Gemi pervanelerinde, pervaneye gelen akım alanının ünifom Gemi pervanesi, Kaldırıcı Yüzey Yöntemi, Kavitasyon, Gürültü, olmaması (iz dağılımının düzensiz olması) ve pervane kanatlarında oluşması muhtemel olan kavitasyon olgusunun meydana gelmesi, hidrodinamik performans açısından istenmeyen etkiler (performans kaybı, erozyon, titreşim, gürültü ) İz meydana getirebilmektedir. Özellikle, pervane kanatları üzerinde oluşan tabaka kavitasyonu büyüklügünün periyodik olarak değişmesi, daimi olmayan pervane kuvvetlerine ve titreşime, su altında ve gemi bünyesinde ise gürültü oluşumuna sebebiyet vermektedir. $\mathrm{Bu}$ çalışmada, geometrisi belli olan ve verilen çalışma koşulları altında kavitasyon gösteren bir gemi pervanesinin tabaka kavitasyonu kaynaklı gürültü tahmini öngörülmüştür. Ayrıca beş farklı gemi arkası iz dağılımının, ele alınan pervanenin performansına, pervane kanadının bir tam devrindeki itme değerlerine ve pervane tarafından gemi üzerindeki bir noktada olușturulan basınç değișimlerine olan etkisi incelenmiştir. Mevcut pervanenin geometrik karakteristiklerinden biri olan çalıklık değeri değiştirilerek (iki farklı çalıklık açısı), bu özelliğin kavitasyon kaynaklı gürültü üzerine olan etkisi parametrik olarak analiz edilmiştir. Aynı zamanda sadece orjinal olan pervane, performans açısından incelenmiștir. Yapılan hesaplamalarda, kaldırıcı yüzey teorisine (lifting surface method) dayalı olan ve gürültü öngörüsü için geliştirilmiş Brown yöntemini kullanan sayısal bir yöntemden yararlanılmıştır. Elde edilen gürültü seviyeleri literatürde yer alan diğer gürültü öngörü yaklaşımları ile karşılaştırılmıştır. İz dağılımının düzensiz olduğu durumlarda çalıklığın etkin bir özellik olarak öne çıktığı görülmüş ve bu çalışma koşullarındaki pervanenin çalıklığı arttırılarak, titreşim ve gürültünün önemli seviyelerde azaltılabileceği sonucuna varılmıştır.
\end{abstract}




\section{Investigation of Cavitation Induced Noise and Effects on Performance of Different Wake Fields in Marine Propellers}

Keywords

Marine propeller, Lifting Surface

Method,

Cavitation,

Noise,

Wake

\begin{abstract}
The fact that the inflow to the marine propeller is not uniform and cavitation phenomenon which is likely to develop on propeller blades may lead to undesirable effects (performance loss, erosion, vibration, and noise) with respect to hydrodynamic performance. Particularly, periodically changing of the sheet cavitation size on the propeller blades leads to unsteady propeller force, vibration, underwater radiated noise as well as noise in the ship. In this study, prediction of sheet cavitation induced noise of a marine propeller whose geometry and wake distribution are known, were examined. Cavitation was present in all given operating conditions. Further investigations were carried out for the target propeller to observe the effect of five different wake distributions on propeller performance, thrust values on the propeller blade for one rotation, and changing of propeller induced pressure pulse at a point on the hull. By changing skew value (two different skew angle), which is one of the geometric characteristics of original propeller, the effect on the cavitation induced noise was analyzed parametrically. The current study includes a discussion for only the original propeller in terms of performance (thrust, torque and efficiency). A numerical approach, based on Brown's method and lifting surface method, was used to predict noise calculations. Noise levels obtained from calculations were compared to the other noise predictions in literature. It can be seen that skew has an effect in cases where the inflow is non-uniform. It can be concluded that vibration and noise levels can be reduced significantly by increasing the skew value of the propeller in these operating conditions.
\end{abstract}

*Sorumlu yazar: Serkan Ekinci:ekinci@yildiz.edu.tr

\section{Giriş}

Bir gemi dizaynında, geminin performansını önemli ölçüde etkileyen en önemli unsurlardan biri, ize uyumlu, optimum sirkülasyon dağılımını veren hatve oranlarına ve kanat kesit geometrisine sahip, kavitasyon göstermeyen ve gemi kıç bölgesine uygun bir şekilde yerleştirilen optimal pervanenin seçilmesidir. Pervane imalatı öncesi yapılan hesaplamalı akışkanlar mekaniği analizleri ile gemi arkası iz dağılımına uygun olarak seçilen optimal pervanede, kavitasyon kaynaklı gürültü, titreşim, erozyon ve performans kaybı gibi etkiler de en aza indirilebileceğinden gemi için çok daha emniyetli bir seyir imkanı sağlanacaktır.

Su altı gürültüsünün üç temel kaynağı olduğu bilinmektedir. Bunlar; makine 
S.Ekinci / Gemi Pervanelerinde Kavitasyon Kaynaklı Gürültü ve Farklı İz Alanlarının Pervane Performansına Etkisinin İncelenmesi

gürültüsü, pervane kaynaklı gürültü ve akış kaynaklı gürültüdür. Su altı akustiği konusunda yapılan çalışmalar, en önemli gürültü kaynağının, pervane sistemleri olduğunu göstermektedir. Pervane gürültüsünün en büyük sebeplerinden biri de pervanenin çalışması esnasında meydana gelebilen ve bir akışkanlar mekaniği olgusu olan kavitasyon olayıdır. Kavitasyon olayında meydana gelen, gelişen ve belirli bir seviyeye geldikten sonra patlayan kabarcıklar, şok dalgaları meydana getirmekte ve bunun sonucunda da gürültü oluşturmaktadır. Gemi pervanelerinde en sık karşılaşılan ve en fazla gürültü seviyesine neden olan kavitasyon türünün ise tabaka kavitasyonu olduğu bilinmektedir. Pervanelerin çalıştığı ortamdaki akışın düzgün olmaması, oluşması muhtemel tabaka kavitasyonunun zamana göre düzensiz bir davranış göstermesi, şaft yolu ile gemi bünyesinde titreşim oluşumuna ve özellikle de su altında gürültü oluşumuna öncülük etmektedir.

Diğer yandan gemi pervanelerinin çalıştığı akışkan ortamı düzensiz bir iz dağılımına sahip olup, bu iz dağılımının optimal pervane dizaynı ve analizi için uygun bir şekilde temsil edilmesi ve hesapların bu yönde gerçekleştirilmesi gerekmektedir [1,2]. Bugüne kadar bu konular ile ilgili olarak gerek sayısal gerekse de deneysel birçok çalışma yapılmıș ve halen de yapılmaya devam etmektedir.

Günümüzde bilgisayar teknolojisindeki gelişimlere paralel olarak, düzenli (uniform) ve düzensiz (non-uniform) iz ortamında gemi pervanelerinin dizaynı ve gürültü/performans analizleri için birçok yöntem mevcuttur (Kaldırıcı hat, kaldırıcı yüzey, sınır eleman yöntemi, sonlu hacim yöntemi vb.)

Deneysel yöntemler, pervane dizaynı ve analizi için, büyük oranda güvenilir sonuçlar verdiği için halen güncelliğini korumaktadırlar. Ancak bu yöntemler, zaman ve maliyet açısından önemli paylar olușturmaktadır. $\mathrm{Bu}$ nedenle, deneysel yöntemlerin yerini alabilecek seviyede, gelişmiş farklı pervane dizaynı ve analiz teorileri/yöntemleri (kaldırıcı hat yöntemi (LLM), kaldırıcı yüzey yöntemi (LSM), sınır eleman yöntemi $(\mathrm{BEM}) /$ panel yöntemi, hesaplamalı akışkanlar dinamiği yöntemi (CFD), girdap-ağ yöntemi (VLM) vb.) pervane hidrodinamiğinde yerini almıștır. Bugüne kadar, kavitasyon (özellikle tabaka kavitasyonu ve uç girdap kavitasyonu) ve kavitasyon kaynaklı etkilerin (titreşim, performans kaybı, özellikle de gürültü) incelenmesi için, söz konusu bu sayısal yöntemlere dayalı olan birçok çalışma yapılmış ve halen de yapılmaya devam edilmektedir.

Fine vd. [3] ve Kim vd. [4] tarafından,, düzensiz akış ortamında kavitasyonlu pervaneler için lineer olmayan potansiyele dayalı bir sınır eleman yöntemi sunulmuştur. Kinnas vd. [5,6] tarafından, pervanelerde görülen gelişmiş uç girdap ve tabaka kavitasyonunun öngörüsü için bir yöntem ele alınmıştır. Kulczyk [7] tarafından, bir hesaplamalı akışkanlar dinamiği paket programı olan FLUENT yardımıyla DTMB 4119 pervanesinin analizi gerçekleștirilmiștir.

Okamura ve Asano [8], gemi pervanelerindeki geniş band gürültü seviyelerinin öngörüsü için yarı-ampirik bir formülü kullanarak çeşitli analizler gerçekleștirilmiştir. Salvatore ve Ianiello [9] ise kavitasyonlu gemi pervaneleri tarafından indüklenen akustik basınç alanı hesabı için sayısal bir öngörü yöntemi sunmuştur. Lee ve Kinnas [10] tarafından, DTMB 4148 pervanesi için, pervanenin ele alınan test koşullarında, kanat üzerinde görülen tabaka kavitasyon bölgeleri, üç farklı kanat 
S.Ekinci / Gemi Pervanelerinde Kavitasyon Kaynaklı Gürültü ve Farklı İz Alanlarının Pervane Performansına Etkisinin İncelenmesi

pozisyonu için karşılaştırmalı olarak gösterilmiştir. . Seol vd. [11] ise, su altında çalıșan bir pervanenin kavitasyonsuz ve tabaka kavitasyonunun etkili olduğu durumlardaki gürültü seviyeleri için sayısal bir çalışma yapmıștır. . Cheolsoo vd. [12] tarafından, kavitasyon tüneli içerisindeki pervane gürültüsünün öngörme yöntemi üzerine çalışılmıştır. Testa vd. [13], farklı pervane akış modellemesinin etkisi ve özellikle gürültü analizi üzerinde etkili olan pervanenin indüklediği takip eden iz dağılımlarının gürültü üzerine etkisini incelemiștir.

Tabaka kavitasyonu kaynaklı gürültü üzerine yapılan teorik araştırmalar, panel yönteme dayalı hidrodinamik model ile Ffowcs Williams-Hawkings denklemini içine alan panel yönteme dayalı hidroakustik modelin birleşiminden oluşan yöntemler, Salvatore ve Ianniello tarafindan yapılan yapılan çalışmalarda yer almaktadır [9]. Odabaşı [14] ise kavitasyon gürültüsüne dair yayınlanmış çalışmaların, aslında kavitasyon başlangıcı ve kavitasyon geometrisinin belirlenmesi ile ilişkili olduğu belirtmiștir.

Fraser [15], BMT tarafından geliştirilmiş yöntemler kullanılmış ve seçilen bir gemi dizaynı için kavitasyonun oluşma ihtimali üzerine hesaplama yöntemi sunmuştur. Atlar vd. [16], balıkçı teknelerinin model pervanelerine ait kavitasyon tüneli testlerinde gürültü ölçümleri ile pervaneye ait düşük gürültü performanslarının, tam ölçekli pervaneler ile uyumlu olduğu göstermiştir.

Takinacı ve Taralp [17] pervanelerin geniș band gürültülerine ampirik bir tahmin yöntemini bulmayı hedeflemiştir.. $\mathrm{Bu}$ yöntem, iki kısımdan oluşmaktadır. Birincisi, pervane üzerindeki kavitasyon modelini doğru bir şekilde sağlayarak, iyi oluşturulmuş bir kaldırıcı yüzey yöntemi ile frekansa bağlı geniş band gürültüsünün ampirik tahmini. İkinci kısım ise gürültü geçișinin zamana bağlı tahminidir. Vassenden ve Lovik [18] tarafından yapılan çalışmada, kavitasyon gürültü kaynakları ve bunların karakteristik özellikleri üzerinde durulmuştur. Aktaş vd. [19] tarafından, bir katamaran araștırma gemisine ait $214 \mathrm{~mm}^{\prime}$ lik model pervanenin, sistematik kavitasyon tünel testleri yapılmıştır. Düzgün ve eğimli şaft akışı koşullarındaki pervane verimi, kavitasyon ve sualtında yayılan gürültü karakteristikleri araştırılmıştır. Özden vd. [20] ise gemiler tarafından oluşan sualtı gürültüsünün temel nedeninin pervane olduğu ve sualtı gürültü karakteristiklerini tahmin ederek kontrol altına almanın önemli olması nedeniyle temel olarak yayılan gürültünün sayısal olarak hesaplanması gerçekleştirmiştir.

Szantyr [21], gemi hidrodinamiğinde kullanılan güncel hesaplama yöntemleri hakkında bilgi vermiştir. Önemli uluslararası toplantılarda sunulan çalışmaları da temel alarak, hesaplamalı akıșkanlar mekaniği yöntemlerinden kaldırıcı yüzey, sınır eleman yöntemi, RANS ve Large Eddy yöntemleri ele alınmıştır. Wittekind ve Schuster [22], tam ölçekli gemilerin bir kısmında yapılmıș, düșük frekans spektrumu dar band bölgesi ile ilgili gözlemleri sunmuştur. [Kowalczyk ve Hoffmann [23] farklı yükleme koşullarında, pervanelerin hidroakustik karakteristikleri, kavitasyonlu ve kavitasyonsuz durumlar için incelemiştir.

Ghassemi [24] ise ise gemi pervanelerinin performansı üzerinde çalıklık ve iz dağılımının etkisi potansiyele dayalı bir sinır elaman yöntemini kullanılarak incelemiştir. Abromowski [25] asimetrik bir kıc formuna sahip geminin pervane 
performası ve iz dağılımı CFD yöntemi ile incelemiștir.

Mevcut çalıșmada, düzensiz akım ortamında çalışan ve kavitasyon gösteren bir gemi pervanesinin, gürültü seviyesi öngörüsü ve farklı iz dağılımlarında performansı üzerine sayısal bir çalışma yapılmıștır. Bunun için, gemi pervanelerinin performansını, tabaka kavitasyon analizini ve kavitasyon kaynaklı gürültü öngörüsünü gerçekleștirebilen, temeli Szantyr'ın kaldırıcı yüzey yöntemine dayanan ve geliştirilmekte olan bir yöntem kullanılmıştır. Sayısal hesaplamaların gerçekleştirilmesi için, kullanılan yönteme dayalı ve FORTRAN programlama dili ile yazılmış olan bir bilgisayar kodundan (PKAV) yararlanılmıștır. Pervanenin performans, kavitasyon ve buna bağlı olarak gürültü öngörüsünü (geliştirilmiş Brown yöntemine dayalı) gerçekleştirebilmek için parametrik sayısal çalışmalar gerçekleştirilmiştir. $\mathrm{Bu}$ amaçla söz konusu pervanenin geometrik karakteristiklerinden olan çalıklık miktarı değiștirilmiştir. Böylece farklı geometriye sahip olan yeni bir pervane elde edilmiștir. Orjinal pervane ile birlikte elde edilen yeni geometriye sahip pervane sayısal olarak analiz edilerek, kavitasyon kaynaklı gürültü seviyeleri ve farklı gemi arkası iz durumları için performans açısından elde edilen sonuçlar (itme, tork, verim, indüklenen basınç değişimleri) sunulmuştur. Tüm hesaplamalar, pervanenin dizayn ilerleme sayısında $\quad(J=0.476)$ gerçekleștirilmiştir. Gürültü öngörüsü ile ilgili gerçekleştirilen hesaplamalarda pervanenin sadece Durum 2 ile belirtilen iz dağılımı dikkate alınmıștır.

\section{Kaldırıcı Yüzey Yöntemi}

Bu çalışmada, temeli Szantyr 'ın kaldırıcı yüzey yöntemine dayalı olan, düzenli olmayan akım ortamında çalışan gemi pervanelerinin performansını (itme,tork ve verim), kanatları üzerindeki kavitasyon büyüklüklerini (basınç dağılımı, kavitasyon alanı) ve kavitasyon kaynaklı gürültü seviyelerini öngörebilen bir yöntem kullanılmıştır. Bu yöntemde, pervane kanatları üzerindeki hidrodinamik yükler kesitlerin sehim hatları üzerine dağıtılan girdap dağılımları ile temsil edilirken, kesit kalınlıkları ise aynı yüzeylere yayılan kaynak/kuyu dağılımları ile modellenmektedir. Benzer șekilde, kanatlar üzerinde oluşması muhtemel kavitasyon ise yine kaynak dağılımları ile temsil edilmektedir. Bu olay, orijinal kanat geometrisi üzerindeki deformasyon şeklinde hesaplara dahil edilmektedir. Kinematik sınır koşulu kaldırıcı yüzey denklemi formülasyonunun temelini olușturmaktadır. $\mathrm{Bu}$ koșul, kaldırıcı yüzeye gelen bileşke akım hızının bu yüzeye teğet olmasını gerektirmektedir. Bu yöntemin daha detaylı açıklaması için Szantyr [26]'dan numaralı kaynaktan yararlanılabilir.

\subsection{Tabaka Kavitasyonu Kaynaklı Gürültü Tahmini}

Pervane kaynaklı gürültü ve özellikle de pkavitasyon kaynaklı gürültü, gemi akustiği açısından en önemli gürültü kaynakları olarak bilinmektedir. Kavitasyon gürültüsünün teorik olarak tahmini, kavitasyonsuz pervaneye nazaran çok daha zordur. Pervane hidrodinamiğinde akustik hesaplamalar genellikle $1 / 3$ oktav band için ve $10-100$ $\mathrm{kHz}$ frekans aralığında yapılmaktadır. Burada, frekans üst band limiti, alt band limitinden $2^{1 / 3}$ kat daha büyüktür. Pervane kavitasyonu nedeniyle yayllan gürültü iki kısımdan olușur. Bunlardan biri "tonal gürültü" diğeri ise "geniș band gürültüsü" olarak adlandırılmaktadır. Mevcut çalışmada sadece geniş band gürültü seviyesi, Takinacı ve Taralp [17] tarafindan denklem (2) ile verilen 
geliştirilmiş Brown formülü kullanılarak hesaplanmıştır.

Orjinal Brown'un yarı ampirik formülünde (1), pervane üzerinde oluşan tabaka kavitasyonu süpürme alanına göre gürültü öngörüsü yapılmasına rağmen ([8],[27]), geliştirilmiş Brown formülünde, pervane kanat uçlarında meydana gelebilecek uç girdap kavitasyonunun etkisi de sisteme dahil edilmistir.

(Orjinal Brown formülü)

$$
L_{S}=163+10 \log \frac{Z D^{4} n^{3}}{f^{2}}+10 \log \frac{A_{C}}{A_{d}}
$$

(Geliştirilmiş Brown formülü)

$L_{S}=163+10 \log \frac{Z D^{4} n^{3}}{f^{2}}+10 \log 40 \frac{A_{C}}{A_{d}}+K_{T i p} \log \frac{V_{T i p}}{V_{T i p}^{i}}+10 \log H$

$$
\mathrm{A}_{\mathrm{C}}=\int_{0}^{2 \pi} \int_{\mathrm{r}_{\mathrm{E} 1}}^{\mathrm{r}_{\mathrm{E} 2}} \mathrm{rdrd} \theta
$$

$$
A_{d}=\pi D^{2} / 4
$$

Burada $A_{C}$ değeri tabaka kavitasyonu süpürme alanı olup, denklem (3) ve Şekil 1'deki gibi tanımlanmaktadır. Özellikle tabaka kavitasyonu kaynaklı gürültü öngörü hesaplamalarında en önemli değişken denklem (3) ile tanımlanan kavitasyon süpürme alanıdır. $\mathrm{Bu}$ çalışmada sunulan kaldırıcı yüzey yöntemi yardımıyla, söz konusu bu değişken sayısal olarak belirlenebilmektedir.

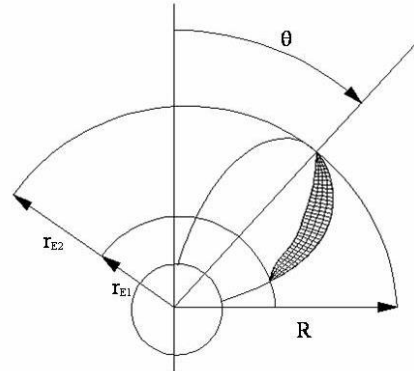

Şekil 1. Kavitasyon süpürme alanının tanımı

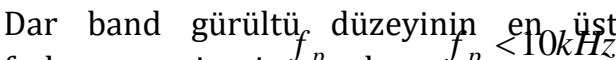
frekans seviyesi ${ }^{p}$ olup,

olduğu durumlarda denklem (2) geçerli olmaktadır. ${ }^{p}$ frekans değeri, pompa kavitasyonu ile ilişkili olarak aşağıdaki formüller yardımiyla belirlenmektedir $[\varnothing], 1 \frac{1 \neq 90}{D}\left(\frac{\sigma_{n}^{l}}{\sigma_{n}}\right)^{-5.2 /}\left(\frac{P_{S}}{22}\right)^{1 / 3} \Rightarrow\left(\frac{\sigma_{n}^{i}}{\sigma_{n}}\right)^{2}<1.7$ $f_{p}=\frac{1100}{D}\left(\frac{\sigma_{n}^{i}}{\sigma_{n}}\right)^{-2.0 / 6}\left(\frac{P_{S}}{22}\right)^{1 / 3} \Rightarrow\left(\frac{\sigma_{n}^{i}}{\sigma_{n}}\right)^{1 / 2} \geq 1.7$

KavitasyP̣n \$ąyısı aşağıda gösterildiği gibi tanı $\overline{\bar{m}}$ anmaktadır.

$$
\frac{1}{2} \rho n^{2} D^{2}
$$

Kavitasyon başlangıç sayısı ise aşağıdaki formülden elde edilmektedir.

$\frac{A_{C}}{A_{d}}=\left[\left(\frac{\sigma_{n}^{i}}{\sigma_{n}}\right)^{1 /{ }_{2}}-1\right]\left(\frac{\sigma_{n}^{i}}{\sigma_{n}}\right)^{-}$
Denklem
(2)
$f=f_{p}$ iken, en üst
frekanstaki gürültü seviyesini vermektedir.
Diğer frekans değerleri için gürültü seviyesi ise aşağıdaki formüller yardımıyla verilmektedir. 
S.Ekinci / Gemi Pervanelerinde Kavitasyon Kaynaklı Gürültü ve Farklı İz Alanlarının Pervane Performansına Etkisinin İncelenmesi

$L_{S}=A f^{0.007} \Rightarrow f<f_{p}$

$L_{S}=B f^{0.2} \Rightarrow f>f_{p}$

Denklem (8)'de yer alan $A$ ve $B$ sabitleri, gürültü spektrumunun devaml karakteristiklerinden elde edilmiştir.

$A=\left(\frac{L_{S p}}{f_{p}}\right)^{0.007} ; B=\left(\frac{L_{S p}}{f_{p}}\right)^{-0.2}$

Denklem $_{L_{S}}(9)_{f}^{\prime}$ da belirtilen gürültü seviyesi $L_{S p}, f_{p}$ üst nokta frekansının kullanılması ile elde edilen gürültü seviyesidir.

Denklem (9), denklem (2) ile birlikte, frekansın bölgesine göre, dar band gürültü spektrumlarının elde edilmesine olanak sağlamaktadır.

\section{Bulgular}

Çalıșmada ele alınan pervaneye ait karakteristik değerleri Tablo 1'de verilmektedir.

Performans, bir tam devirdeki itme değişimi ve indüklenen basınç dağılımlarının hesaplanmasında kullanılan dört farklı nominal iz dağılımı (bir adet iz dağılımı da açık su durumunu ifade etmektedir) Şekil 2'de verilmektedir.

Söz konusu beş farklı iz dağılımı, ele alınan pervanenin çapına bağlı olarak, pervane disk alanını kapsayacak şekilde düzenlenmiştir.

Ayrıca, söz konusu farklı gemi arkası iz durumlarina ait gemilerin tipleri ve ortalama iz katsayısı değerleri Tablo 2 'de, pervaneye ait geometrik değerler ise Tablo 3'te verilmiştir.
Tablo 1. Pervane karakteristikleri

\begin{tabular}{|l|l|}
\hline Gemi hızı $V(\mathrm{~m} / \mathrm{s})$ & 6.688 \\
\hline Pervane devri $n(1 / \mathrm{s})$ & 2.5 \\
\hline Pervane çapı $D(\mathrm{~m})$ & 3.8 \\
\hline Şaft derinliği $(\mathrm{m})$ & 5 \\
\hline Kanat sayısı & 4 \\
\hline $\begin{array}{l}\text { Dizayn ilerleme } \\
\text { katsayısı }\end{array}$ & 0.476 \\
\hline $\begin{array}{l}\text { Göbek/çap oranı } \\
\text { Çalıklık açısı }\end{array}$ & 0.276 \\
\hline Eğiklik & $\varphi=21.8^{\circ}$ \\
\hline Dönme yönü & $0^{\circ}$ \\
\hline
\end{tabular}

Tablo 2. Ortalama iz katsayıları ve gemi tipleri

\begin{tabular}{|l|l|l|}
\hline Durum & Wort. & Gemi tipi \\
\hline Durum 1 & 0 & Açık su durumu \\
\hline Durum 2 & 0.323 & $\begin{array}{l}\text { Ana gemi } \\
\text { (Tanker) } \\
\left(C_{B}=0.498\right)\end{array}$ \\
\hline Durum 3 & 0.329 & $\begin{array}{l}\text { Kimyasal tanker } \\
\left(C_{B}=0.531\right)\end{array}$ \\
\hline Durum 4 & 0.150 & $\begin{array}{l}\text { Fırkateyn } \\
\left(C_{B}=0.39\right)\end{array}$ \\
\hline & & $\begin{array}{l}\text { Araştırma gemisi } \\
\text { (Seiun-maru) } \\
\text { (C } B=0.576)\end{array}$ \\
\hline Durum 5 & 0.215 \\
\hline
\end{tabular}

İlk olarak, pervane geometrisinin tabaka kavitasyonu üzerinde olan etkisini incelemek için, orjinal çalıklık açısı $\left(\varphi=21.8^{\circ}\right)$ diğer tüm geometrik değerler sabit kalmak koşulu ile $\varphi=50.19^{\circ}$ olacak şekilde değiştirilerek farklı bir pervane geometrisi elde edilmiştir (Şekil 3). Tüm gürültü analiz hesaplamaları, pervanenin dizayn ilerleme sayısı olan J=0.476 
S.Ekinci / Gemi Pervanelerinde Kavitasyon Kaynaklı Gürültü ve Farklı İz Alanlarının Pervane Performansına Etkisinin İncelenmesi

değerinde ve Durum 2 koşulunda gerçekleştirilmiştir.

Tablo 3. Pervaneye ait geometrik değerler

\begin{tabular}{|c|c|c|c|c|c|}
\hline $\begin{array}{c}\text { Boyutsuz } \\
\text { yarıçap (r/R) }\end{array}$ & $\begin{array}{l}\text { Kiriş } \\
\text { dağılımı c/D }\end{array}$ & $\begin{array}{c}\text { Çalıklık } \\
\text { dağılımı (m) }\end{array}$ & $\begin{array}{c}\text { Hatve } \\
\text { dağılımı } \\
\text { P/D }\end{array}$ & $\begin{array}{c}\text { Kalınlık } \\
\text { dağılımı t/c }\end{array}$ & $\begin{array}{c}\text { Sehim } \\
\text { dağılımı F/c }\end{array}$ \\
\hline 0.3 & 0.171 & -0.017 & 0.722 & 0.247 & 0.025 \\
\hline 0.35 & 0.205 & -0.052 & 0.757 & 0.189 & 0.033 \\
\hline 0.4 & 0.236 & -0.082 & 0.787 & 0.149 & 0.033 \\
\hline 0.5 & 0.289 & -0.122 & 0.833 & 0.099 & 0.029 \\
\hline 0.6 & 0.329 & -0.118 & 0.861 & 0.069 & 0.025 \\
\hline 0.7 & 0.350 & -0.046 & 0.870 & 0.049 & 0.020 \\
\hline 0.8 & 0.346 & 0.110 & 0.858 & 0.036 & 0.017 \\
\hline 0.9 & 0.299 & 0.372 & 0.807 & 0.028 & 0.015 \\
\hline 0.95 & 0.240 & 0.549 & 0.763 & 0.027 & 0.015 \\
\hline 1 & 0.000 & 0.760 & 0.705 & - & - \\
\hline
\end{tabular}
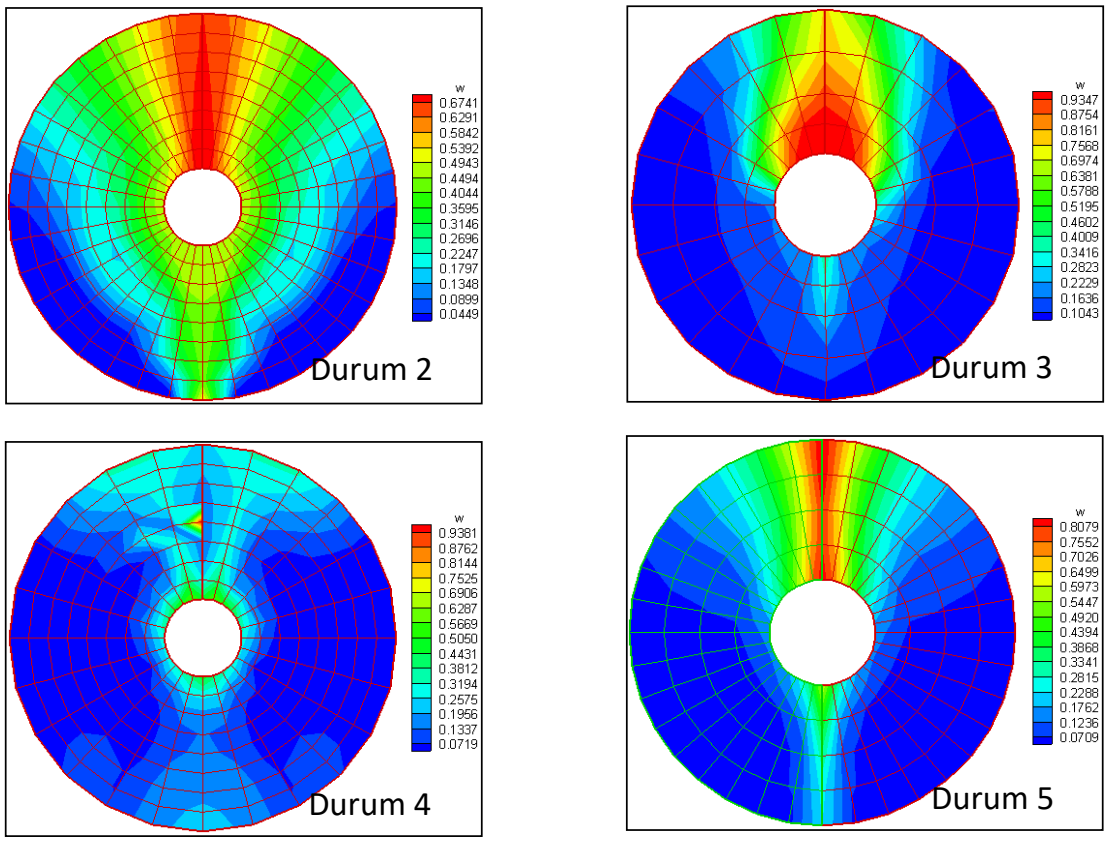

Sekil 2. Pervaneye ait dört adet farklı nominal iz dağılımı

(Durum 2, Durum 3, Durum 4, Durum 5) 

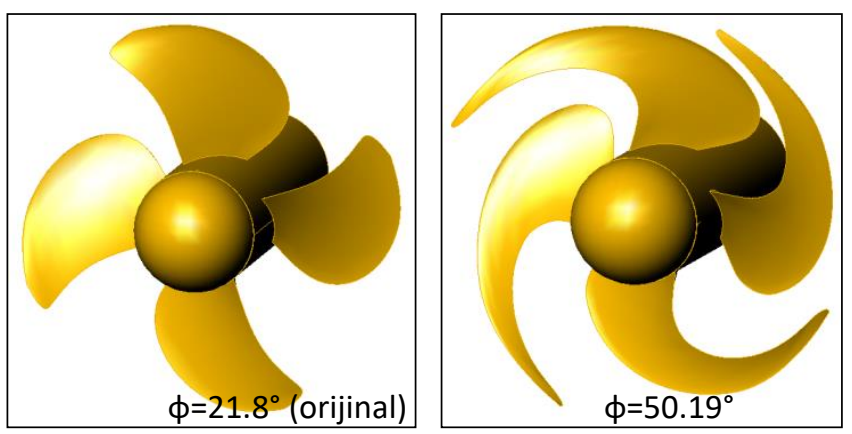

Şekil 3. CAD programı yardımıyla çizilmiş orjinal ve çalıklığı değiştirilmiş pervane

Çalıklığın, pervanenin bir tam dönüşü esnasında kanat üzerinde oluşan tabaka kavitasyonu alanına olan etkisi, kanat pozisyon açlarına göre Şekil 4'te verilmektedir. $\mathrm{Bu}$ şekilden görüleceği üzere, pervanenin çalıklık miktarındaki artış kanatlar üzerinde oluşan tabaka kavitasyonu alanını azalmaktadır. Vurgulamak gerekirse, burada görülen kavitasyon alan değerleri kavitasyon süpürme alanı değil, pervanenin bir tam dönüşü esnasında o anki kanat pozisyonunda elde edilen değerleridir. Analiz kapsamında incelenecek kavitasyon kaynaklı gürültü öngörüsünde, geliştirilmiş Brown formülünde yer alan kavitasyon süpürme alanının $\left(A_{c}\right)$ hesaplanması için, kaldırıcı yüzey yönteminde yer alan denklem (3) kullanılmıştır. İki farklı pervane geometrisi için yapılan analizler sonucunda elde edilen kavitasyon süpürme alanları ise $\varphi=21.8^{\circ}$ çalıklık açısına sahip pervane için $0.265 \mathrm{~m}^{2}$, $\varphi=50.19^{\circ}$ çalıklığa sahip pervane için $0.131 \mathrm{~m}^{2}$ olarak bulunmuştur. Elde edilen bu sonuca göre, çalıklığın kavitasyon süpürme alanını azalttı̆̆ı ifade edilebilmektedir. Ayrıca, çalıklık değişiminin pervane performansına etkisi Tablo 4'te gösterilmektedir. Denklem (2) içinde yer alan uç girdap kavitasyonun etkisini hesaba katmak için, uç girdap kavitasyonu başlangıç anındaki kanat ucu hızı ile devir sayısı değerleri, kaldırıcı yüzey yöntemine dayalı bir kod (PKAV) kullanılarak elde edilmiştir.

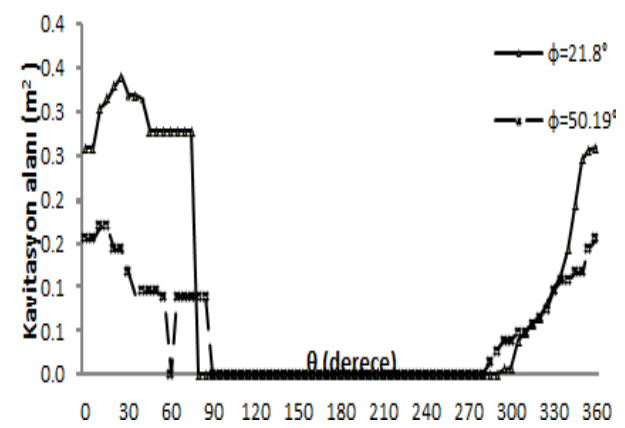

Şekil 4. İki farklı çalıklık açısında, kanat pozisyonuna göre tabaka kavitasyonu alanlarının değiş̧imi

Tablo 4. Çalıklık değişiminin pervane performansina etkisi

\begin{tabular}{|l|l|l|l|}
\hline Çalıklık & İtme $(\mathrm{kN})$ & $\begin{array}{l}\text { Tork } \\
(\mathrm{kNm})\end{array}$ & Verim \\
\hline$\varphi=21.8^{\circ}$ & 275.559 & 150.314 & 0.780 \\
\hline$\varphi=50.19^{\circ}$ & 214.558 & 116.670 & 0.783 \\
\hline
\end{tabular}

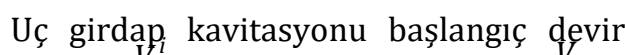
sayısı $\left({ }^{V_{T i p}^{1}}\right)$ ve kanat ucu hızı ( ${ }^{V_{\text {Tip }}}$ ) bulunurken iteratif bir yöntem uygulanmıştır. $\mathrm{Bu}$ değerler sırasıyla; $\varphi=21.8^{\circ}$ çalıklık açısına sahip pervane için 139.2 (1/s), 27.69 (m/s), $\varphi=50.19^{\circ}$ çalıklığa sahip pervane için 163.2 (1/s), 32.47 (m/s) olarak bulunmuştur. Denklem (2)'de yer alan, $H$ değeri; 
S.Ekinci / Gemi Pervanelerinde Kavitasyon Kaynaklı Gürültü ve Farklı İz Alanlarının Pervane Performansına Etkisinin İncelenmesi

gerçekleştirilen analizlerde $5.51 \mathrm{~m}$ olarak karakteristiklerinin birbirine yakın olduğu kabul edilmiștir.

görülmektedir.

Kavitasyon kaynaklı gürültü öngörüsü Elde edilen gürültü seviyelerindeki sayısal için iki farklı geometriye sahip farklılıkların, önerilen formüllerin ampirik pervaneden elde edilen gürültü düzeyleri formüller olmasindan olm $_{1 \leq f(H z) \leq 1000}$ kannaklandığı Şekil 5'te gösterilmiștir.

Şekil 5'ten görüleceği üzere, çalıklık açısı arttıkça kavitasyon etkisi nedeni ile olușan gürültünün seviyesi azalmaktadır.

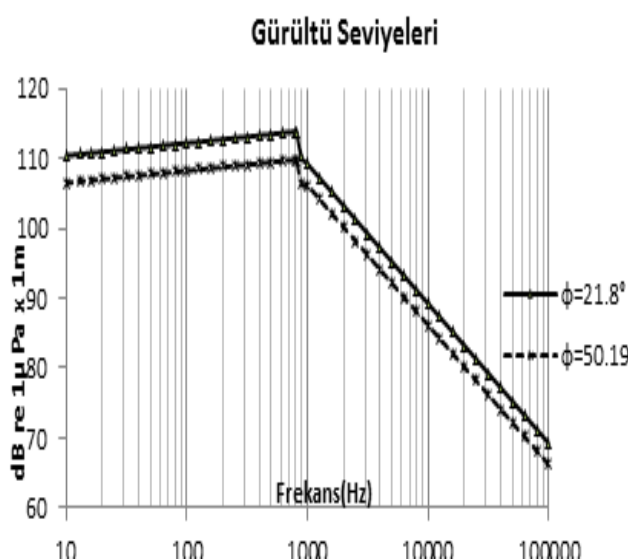

Şekil 5. İki farklı çalıklık açısında kavitasyon kaynaklı gürültü seviyeleri

Kavitasyon olayına dayalı gürültü öngörüleri açısından, geliştirilmiş Brown formülü ile karşılaştırma yapabilmek için, literatürde yer alan farklı gürültü tahmini yaklaşımları ve önerileri ele alınmıștır.

Bu yaklaşımlarda, orjinal Brown yarı ampirik formülü (denklem (1)), ICES (International Council for the Extrapolation of the Sea) tarafindan önerilen formül (denklem (10)) ve [15] numaralı kaynakta verilen formül (denklem (11)) kullanılmıștır.

Bu karșılaștırma, sadece $\varphi=21.8^{\circ}$ çalıklık açısına sahip orijinal pervane için Durum 2 iz alanı dikkate alınarak yapılmıştır.

Elde edilen sonuçlar, Şekil 6'da verilmiştir. $\mathrm{Bu}$ grafikte yer alan eğrilerin

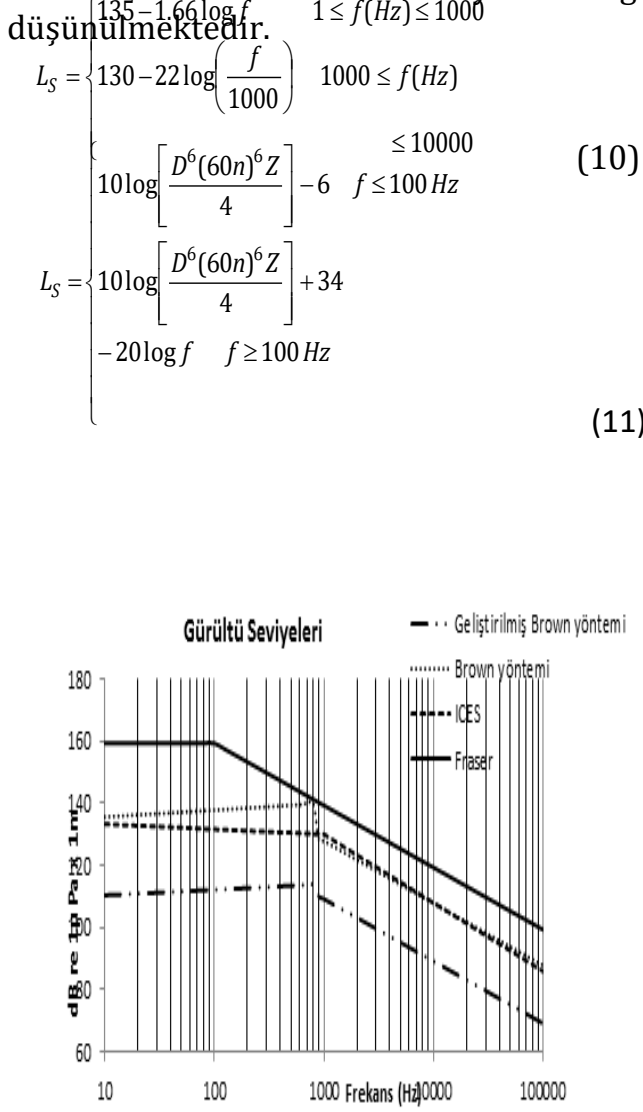

Şekil 6. Orjinal pervaneye ait gürültü seviyelerinin, farklı yaklaşımlara göre karşılaştırılması

Kavitasyon kaynaklı gürültü analizinden sonra, orijinal olan yani $\varphi=21.8^{\circ}$ çalıklık açısına sahip pervanenin farklı beş adet gemi arkası iz dağılımları için analizleri gerçekleştirilmiş, hesaplanan itme katsayısı, tork katsayısı ve verim değerleri, değişik ilerleme sayıları için Şekil 7'de gösterilmiştir. 


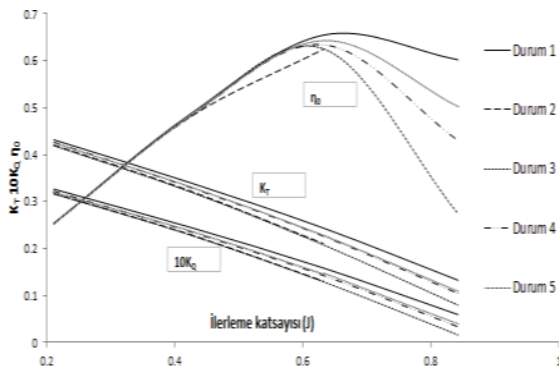

Şekil 7. Farklı ilerleme sayıları ve gemi arkası iz durumları için orijinal pervaneye ait performans karakteristikleri

Şekil 7’ den görüleceği üzere, açık su pervanesinin verimi (Durum 1) beklenildiği gibi en yüksektir. Yaklaşık olarak $J=0.6$ ilerleme katsayısına kadar tüm durumlar için elde edilen verim değerleri birbirlerine yakın olmaktadır. Dizayn ilerleme katsayısında $(J=0.476)$, ana gemi izinde (Durum 2) verim 0.53 iken, Durum 1'de 0.54 tür.

Ayrıca orijinal gemi izindeki verim, açık su veriminden sonra tüm ilerleme sayılarında en yüksektir. $\mathrm{Bu}$ da gemi arkası ile uyumlu olarak orijinal pervanenin iyi dizayn edilmiş olduğunu göstermektedir.

Daha sonra çalıklığın farklı gemi arkası çalışma koşullarında olan etkisini göstermek amacı ile analizler gerçekleştirilmiştir. Şekil 8 ve Şekil 9' da, orjinal pervane ile birlikte çalıklığı değiștirilen yeni pervane geometrisinin farklı iz durumlarında, pervane şaft ekseninden dik bir mesafede (çalışmada bu değer $3 \mathrm{~m}$ olarak alınmıştır) bir tam devirde bir kanat tarafından indüklenen basınç değişimleri, aynı ilerleme sayısında $(J=0.476)$ gösterilmektedir.

Elde edilen sonuçlardan görüleceği üzere; çalıklık miktarı arttıkça, basınç değişimlerinin büyüklüğü her farklı iz durumunda azalmaktadır.

Bu sonuç, pervane kaynaklı titreşimlerin azalmasında çalıklığın önemli bir geometrik parametre olabileceğini göstermektedir.

Aynı zamanda pervane kanadının, gemiye yakın olduğu $0^{\circ}-90^{\circ}$ ve $270^{\circ}-360^{\circ}$ derece aralıklarda en fazla basınç değişimlerine neden olduğu görülmektedir.

Tüm iz durumlarında, pervanenin gemiye yakın olduğu diğer pervane kanat pozisyonlarında ise basınç değişimleri çok küçük seviyelerde kalmaktadır.

Callklkk $=21.8^{\circ}$

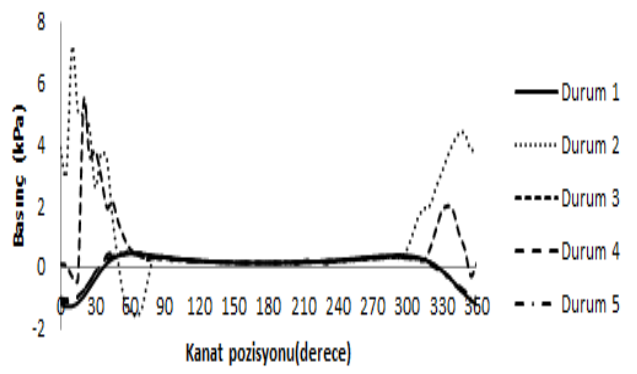

Şekil 8. Orijinal pervane için bir tam devirde elde edilen basınç dalgalanmalarının değişimi

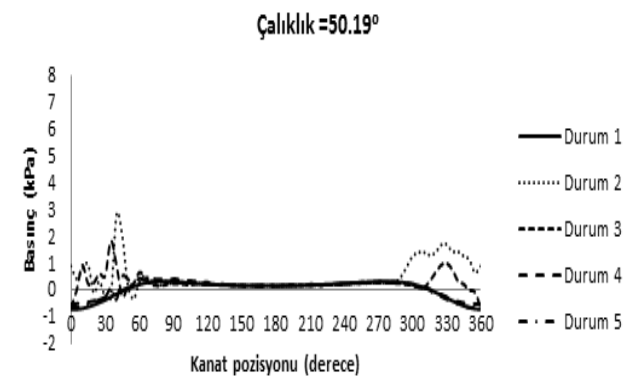

Şekil 9. $\varphi=50.19^{\circ}$ çalıklık değerine sahip pervane için bir tam devirde elde edilen basınç dalgalanmalarının değișimi

Şekil 10 ve Şekil 11'de pervanenin bir tam devri boyunca tek bir kanat tarafından üretilen itme değişimleri her bir iz dağılımı için aynı ilerleme sayısında $(U=0.476)$ gösterilmiştir. 
S.Ekinci / Gemi Pervanelerinde Kavitasyon Kaynaklı Gürültü ve Farklı İz Alanlarının Pervane Performansına Etkisinin İncelenmesi

$\mathrm{Bu}$ şekillerden görüleceği üzere, tüm iz durumlarında çalıklığın artmasına bağlı olarak pervane itmeleri azalmaktadır.

Ayrıca çalıklık miktarı arttıkça, itme eğrilerindeki dalgalanmaların da azaldı̆̆ görülmektedir.

Bu eğilim, pervane kaynaklı titreşimlerin azalmasına öncülük etmektedir.

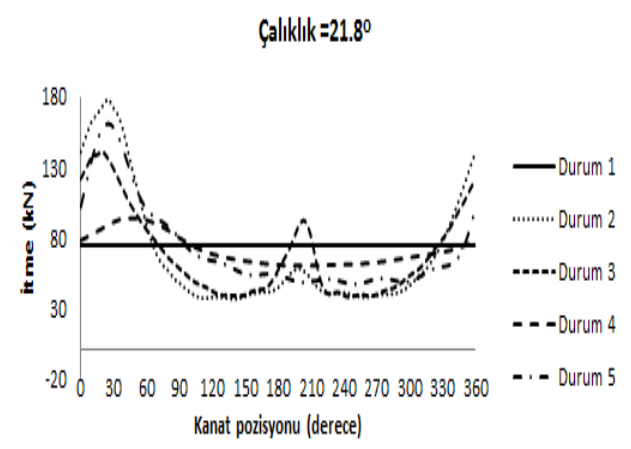

Şekil 10. Orijinal pervane için bir tam devirde tek bir kanat tarafından elde edilen itme değişimi

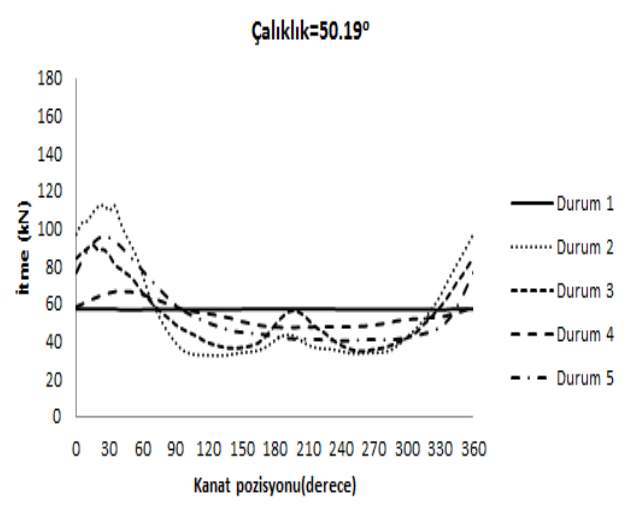

Şekil 11. $\varphi=50.19^{\circ}$ çalıklık değerine sahip pervane için bir tam devirde tek bir kanat tarafından elde edilen itme değișimi

\section{Tartışma ve Sonuç}

Yapılan analizlerde, çalıklık açısındaki artıș ile kanatlarda olușan tabaka kavitasyon alanlarında genel olarak bir azalmanın olduğu görülmüștür.

Dolayısıyla bu azalmanın gürültü seviyesini de düşürdüğü yapılan analizler sonucu tespit edilmiştir. Kavitasyon kaynaklı gürültü düzeylerinin karşılaştırılmasının yapılması amacıyla literatürde yer alan farklı gürültü tahmini yaklaşımları kullanılmıştır.

Daha sonra orijinal pervane $\left(\varphi=21.8^{\circ}\right.$ çalıklık açısına sahip olan) farklı gemi arkası iz durumları için (Durum 1, Durum 2, Durum 3, Durum 4, Durum 5) sayısal olarak test edilmiștir. Illk olarak, bu beș farklı iz koşullarında elde edilen pervane performans eğrileri (verim, itme ve tork katsayısı) karşılaştırılmıştır. $\mathrm{Bu}$ eğrilerden, belirli bir ilerleme sayısına kadar $(J=0.6)$ verim değerlerinde büyük bir değișikliğin olmadığı, orijinal gemi izindeki (Durum 2) verimin tüm ilerleme sayılarında diğer iz durumlarındaki verim değerlerinden daha yüksek olduğu görülmektedir. Çalıklığın, pervane kanadı tarafından indüklenen basınç değişimlerine olan etkisi ile itme değişimlerine olan etkisini incelemek için, orijinal pervane ile birlikte diğer pervane $\left(\varphi=50.19^{\circ}\right.$ çalıklık açısına sahip olan) sayısal olarak analiz edilmiştir. Elde edilen sonuçlardan, artan çalıklık miktarının tüm gemi arkası iz durumları için hem indüklenen basınç değișimlerini hem de itme değişimlerinde meydana gelen dalgalanmaları azalttığı görülmüştür. $\mathrm{Bu}$ durum, pervane kaynaklı titreşimlerin azaltılmasında düzensiz akım ortamı için çalıklığın önemli bir geometrik parametre olduğunu göstermiștir.

Tüm bu elde edilen sonuçlar ışığında, bir gemi pervanesinin dizaynından önce, mutlaka performans verileri, kavitasyon gösterme durumları ve meydana gelecek gürültü hususlarında analizler yapılması ve bu analizlere göre pervane üretiminin gerçekleștirilmesi gerektiği söylenebilir. 
S.Ekinci / Gemi Pervanelerinde Kavitasyon Kaynaklı Gürültü ve Farklı İz Alanlarının Pervane Performansına Etkisinin İncelenmesi

$\mathrm{Bu}$ analizlerin yapılabilmesi için, çalışmada kullanılan benzer sayısal yöntemlere dayalı bilgisayar kodlarının veya hesaplamalı akışkanlar dinamiğine dayalı paket programların kullanılması, zaman ve maliyet açısından pervane tasarımcılarına kolaylık sağlayacaktır. Daha sonra yapılması planlanan çalışmalarda, gemi pervanelerine ait eğiklik (rake), kalınlık, sehim dağılımı gibi geometrik karakteristikler ve farklı iz dağılımları hesaba katılarak, kavitasyon kaynaklı gürültü ve performansa olan etkileri incelenecektir.

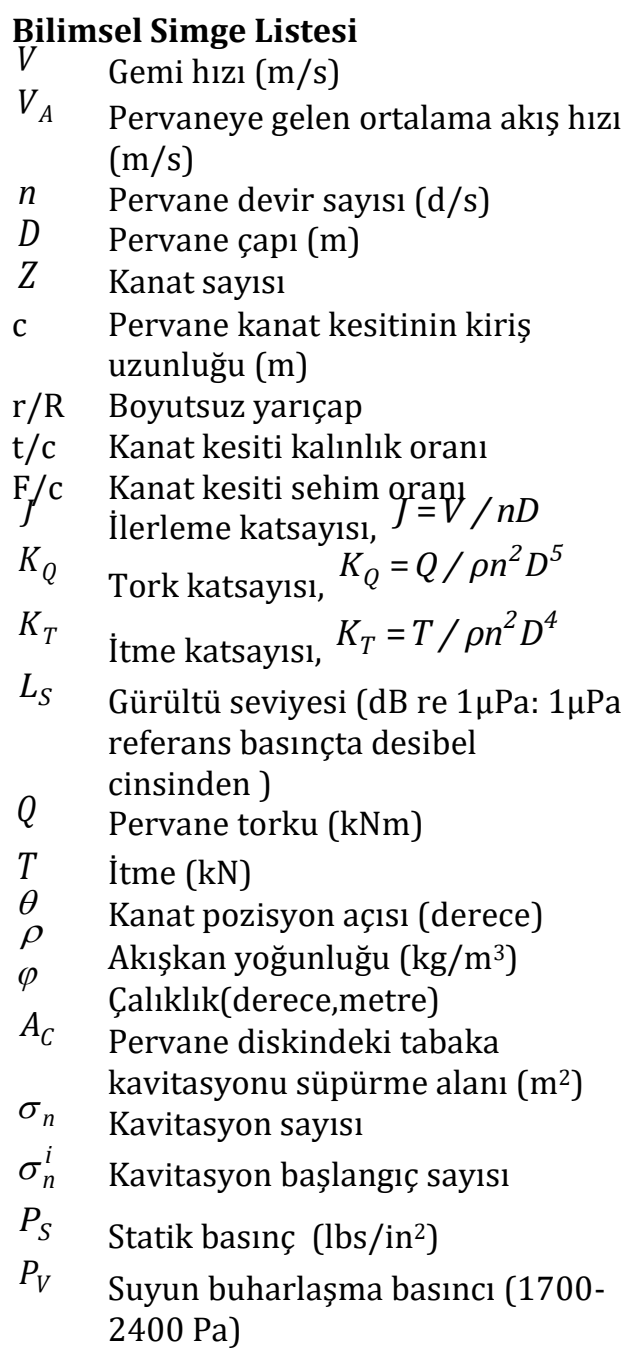

$A_{d} \quad$ Pervane disk alanı $\left(\mathrm{m}^{2}\right)$

$f \quad$ Gürültü frekansı $(\mathrm{Hz})$

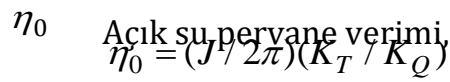

$K_{\text {Tip }}$ 60, uç girdap kavitasyonu için sabit (çok derinde bulunan

$V \quad$ pervane için 80, Kaynak[14])

$V_{\text {Tip }}$ Pervane kanat ucu hızı (m/s)

$V_{\text {Tip }}^{i} \quad$ Uç girdabın oluştuğu başlangıç

$H$ devir sayısı (1/s)

$H \quad$ Hidrofon yerleștirme mesafesi (m)

$C_{B} \quad$ Blok katsayısı

w İz katsayısı, $\mathrm{w}=\left(\mathrm{V}-\mathrm{V}_{\mathrm{A}}\right) / \mathrm{V}$

\section{Kaynakça}

[1] Bal, S.. 2008. Kavitasyon Yapan Gemi Pervanesinin Hidrodinamik Karakteristiklerinin Sayısal Bir Yöntem ile İncelenmesi, Gemi İnşaatı ve Deniz Teknolojisi Teknik Kongresi, Cilt1,s. 239-249,

[2] Bal, S.. 2010. Gemi Pervanelerinin Hidrodinamik Performansı, Tersane, Gemi İnșa Sektörü ve Yan Sanayisi Dergisi, Cilt.17, s. 32-36.

[3] Fine, N. and Kinnas, S.A. 1993b.The Nonlinear Numerical Prediction of Unsteady Sheet Cavitation for Propellers of Extreme Geometry, Proceedings: Sixth International Conference on Numerical Ship Hydrodynamics, August, s. 531-544.

[4] Kim, Y.-G. and Lee, C.-S. 1996. Prediction of Unsteady Performance of Marine Propellers with Cavitation Using Surface Panel Method, Proceedings, 21st Symposium on Naval Hydrodynamics, Trondheim, Norway,s.913-928

[5] Kinnas, S.A., Lee,H. and Young, Y.L. 2002. Boundary Element Techniques for the Prediction of Sheet and Developed Tip Vortex Cavitation, Electronic Journal Boundary Elements, Cilt.BETEQ2001, sayı.2, s.151-178 
S.Ekinci / Gemi Pervanelerinde Kavitasyon Kaynaklı Gürültü ve Farklı İz Alanlarının Pervane Performansına Etkisinin İncelenmesi

[6] Kinnas, S.A., Lee, H. and Young, Y.L. 2003. Modeling of Unsteady Sheet Cavitation on Marine Propellers,International Journal of Rotating Machinery, Cilt 9 (4), s. 263277.DOI:10.1080/102362103902030 08

[7] Kulczyk, J. S.,Skraburski, L. and Zawislak, M. 2007 Analysis of Screw Propeller DTMB 4119 using the FLUENT System, Archives of Civil and Mechanical Engineering, Cilt.7(4) s.129-136

[8] Okamura, N. and Asano, T., 1988.Prediction of Propeller Cavitation Noise and Its Comparison with Full-Scale Measurements, Journal of the Society of Naval Architects of Japan, Cilt 164, s.19-33, December

[9] Salvatore, F. and Ianiiello, S. Preliminary Results on Acoustic Modelling of Cavitating Propellers, International Association for Boundary Element Methods, IABEM 2002, UT Austin, TX, May 28-30

[10] Lee, H., ve Kinnas, S.A.. 2005 A BEM for the Modeling of Propeller Sheet Cavitation Inside a Cavitation Tunnel, Journal of Computational Mechanics, Cilt.37(1):,s.41-51.DOI 10.1007/s00466-005-0696-z

[11] Seol, H., Suh, J.C. and Lee, S. 2005 Development of Hybrid Method for the Prediction of Underwater Propeller Noise, Journal of Sound and Vibration, Cilt.288, s.345-360. DOI: 10.1016/j.jsv.2005.01.015

[12] Cheolsoo P., Hanshin S., Kwangsoo K. and Woojae S. 2009.A Study on Propeller Noise Source Localization in a Cavitation Tunnel, Ocean Engineering, Cilt.36 (9-10): s.754762.DOI:10.1016/j.oceaneng.2009.04. 005

[13] Testa, C., Salvatore, F., Ianniello, S. and Gennaretti, M. 2005. Theoretical and Numerical Issues for Hydroacoustic Applications of the
FfowcsWilliams-Hawkings Equation, Proceeding 11th AIAA/CEAS Aeroacoustics Conference, Monterey, USA

[14] Odabaşı, A.Y. 1987. Cavitation Inception and Prediction of BroadBand Noise Levels, British Maritime Technology, Tech.Rep.W1607, March

[15] Fraser,A., J. 1986.State of the Art in Underwater Noise, Part 3:The Prediction and Minimisation of Propeller Induced Waterborne Noise, British Maritime Technology Limited, Hydromechanics Division, Computational Hydromechanics Dept., February

[16] Atlar, M., Takinaci, A., C.and Korkut, CAV 2001.Cavitation Tunnel Tests for Propeller Noise of a FRV and Comparisons With Full-Scale Measurements, s.1-13.

[17] Takinaci, A., C. and Taralp, T. 2012. Prediction and Simulation of Broadband Propeller Noise, Journal of Marine Science and Technology, Cilt. 21(5), s.538-544. DOI: 10.6119/JMST012-0831-1

[18] Vassenden, J.and Lovik, A. 1978. Basic and Applied Aspects of Scaling Cavitation Noise, The Ship Research Institute of Norway, December, Trondheim, Norway

[19] Aktaş, B., Türkmen, S.,Korkut, E., Fitzsimmons, P. and Atlar, M. 2014.Systematic Cavitation Tunnel Tests of a Propeller in Uniform and Inclined Flow Conditions as Part of a Round Robin Test Campaign, A. Yücel Odabaşı Colloquium Series 1st International Meeting - Propeller Noise \& Vibration 6th - 7th November İstanbul, Türkiye.

[20] Özden, M., C., Gürkan, A., Y., Özden, Y., A., Canyurt, T. G. and Korkut, E. 2014. Underwater Radiated Noise Prediction for a Submarine Propeller in Different Flow Conditions, A. Yücel Odabașı Colloquium Series 1st International Meeting - Propeller 
Noise \& Vibration 6th - 7th November İstanbul, Türkiye.

[21] Szantyr J.A.2008. The Crucial Contemporary Problems of The Computational Methods for Ship Propulsor Hydrodynamics, Gdańsk University of Technology,Archives Of Civil and Mechanical Engineering, VIII (1), Gdańsk University of Technology, Poland

[22] Wittekind, D. ve Schuster, M. 2014. Propeller Cavitation Noise and Background Noise in the Sea, A. Yücel Odabaşı Colloquium Series 1st International Meeting - Propeller Noise \& Vibration 6th - 7th November İstanbul, Türkiye.

[23] Kowalczyk, S. ve Hoffmann, P. 2014. Propeller Noise Investigations by Means of Middle Size Cavitation Tunnel Measurements, A. Yücel Odabașı Colloquium Series 1st International Meeting - Propeller Noise \& Vibration 6th - 7th November İstanbul, Türkiye.

[24] Ghassemı, H. 2009. The Effect of Wake Flow and Skew Angle on the Ship Propeller Performance, Scientia Iranica Transaction B-Mechanical Engıneerıng, Cilt.16(2), s.149-158

[25] Abramowski, T. et al. 2010. Numerical analysis of effect of asymmetric stern of ship on its screw propeller efficiency, Polish Maritime Research, Cilt.17(4), s. DOI:13-16. 10.2478/v10012-010-0030-3

[26] Szantyr, J.A. 1994 A method for analysis of cavitating marine propellers in non-uniform flow, International Shipbuilding Progress, Cilt.41(427, s.223-242.

[27] Yoshimura, Y. ve Koyanagl, Y. 2004. Design of a Small Fisheries Research Vessel with Low Level of UnderwaterRadiated Noise, Journal of the Marine Acoustic Society of Japan, Cilt. 31 (3): s.1-9. 